\title{
Interactive Virtual Campus Tour using Panoramic Video: A Heuristic Evaluation
}

\author{
Aznoora Osman ${ }^{1 *}$, Nur Izlin Iskak ${ }^{2}$, Nadia Abdul Wahab ${ }^{3}$, Norfiza Ibrahim ${ }^{4}$ \\ ${ }^{1,2,3,4}$ Faculty of Computer and Mathematical Sciences \\ Universiti Teknologi MARA, Perlis Branch, Arau Campus, 02600 Arau, Perlis, Malaysia \\ Corresponding author: *aznoora@uitm.edu.my \\ Received Date: 29 September 2020 \\ Accepted Date: 22 October 2020
}

\begin{abstract}
Difficulty in finding the destination around a campus is a common problem faced by students, staffs and visitors of a university. Outdated signboards, confusing building architecture and layout, and bad weathers are just some of the hindrance to find location for people who are unfamiliar with the campus area. To solve the problem, virtual campus tour is chosen because it can also be embedded into a university website, or use as a stand-alone app. The virtual campus tour app can help users in visualizing their journey around campus because it was developed using collections of panoramic video footage, which allows user to watch in 360-degree view of selected campus area. Administrative building, academic blocks and residential college are some of the destinations included in the tour. A heuristic evaluation of system usability was conducted with five university lecturers who have vast experience in the computer science field. The purpose is to identify usability problems in the user interface of the app, by judging its compliance with standard usability principles. Comments from experts were used to make refinement before it could be further tested with potential users.
\end{abstract}

Keywords: virtual tour, campus tour, heuristic evaluation

\section{INTRODUCTION}

A virtual tour is the reproduction of actual location with the help of consecutive still images. It can help in renewing a realistic presentation of reality (Bakre, Deshmukh, Sapaliga, \& Doulatramani, 2017). The use of virtual tour began in 1994 and has ever since spreaded throughout the world in line with the circulation of time and advanced technology. The virtual campus tour has become a phenomenon today, where user can access it via their mobile phone or personal computer. A virtual campus tour is a digital tour of a specific location in colleges or universities that includes 2D panoramic images and a series of video images or hyperlinked imagery, where hotspots are used to attach these panoramas to one another (Koyuncu \& Kocabasoglu, 2008). Additionally, Namsong (2009) asserted the idea of virtual campus tour, that include videos consisting of an arrangement of images and audio, could provide numerous benefits for demonstration and instructional functions.

Tourist attraction places, universities, and schools are some of the suitable areas for virtual tour. For example, Wook, Zairon, Idris, Zin, Judi and Jailani (2018) demonstrated interaction design of web-based virtual campus tour that could enhance the experience of exploring the natural environment around campus in the absence of physical presence at the university. Beside that, from their current location, users could view virtual tour of adjacent destinations in the campus, which offers more realistic and catchy appearances (Widiyaningtyas, Prasetya and Wibawa, 2018). Also, Perdana, Irawan, and Munadi (2019) and Rohizan, Vistro, and Puasa (2019) revealed that virtual campus tour could be used to introduce university buildings and to enhance visitor experience. 
In UiTM Perlis, there are many old and new buildings, located scatteredly around its 335 acre campus. Hence, these areas are not necessarily known among staffs, students and visitors. Problems arise when trying to locate a certain building because of unfamiliarity with the destination, outdated signboards and confusing layout among new and old buildings, due to varied architectural design.

\section{METHODOLOGY}

In carrying out the study, Agile methodology was used as development methodology because it is an iterative and incremental based, with solid integration between development and testing throughout its lifecycle (Sharma, Sarkar, \& Gupta, 2012). During the requirement phase, a groundwork was established via a preliminary investigation (PI) to confirm that the problems exist. Therefore, a brief online survey, lasted for three days, was administered using Google form. Its link was shared via the Whatsapp messaging service and received responds from 14 university students and nine university visitors. Though only a small number, but from a qualitative point of view, the feedbacks received were valuable and provided insights in determining the functional requirements of a virtual campus tour.

There were three open ended questions that required the respondents to specify how they search for a destination inside a campus area and the problems they faced. It was discovered that most respondents experienced almost similar issues when finding destinations around campus, such as having to ask for direction from passersby repeatedly, navigating around confusing building layouts, reading outdated signage, and for some, finding no signboard at all to identify a particular location. Bad weather such as heavy rain also was reported as the difficulty when trying to find buildings.

Based on these findings, the possible solutions were defined. For functional requirements, a virtual campus tour that is based off panoramic videos were selected as the technology to be used because it offers dynamic 360 degree experience while watching it, as compared to traditional photo-stitching based virtual tour. It should be able to show a complete journey, so that users could view the correct path to reach his or her intended destination. Furthermore, it should represent popular destinations in the campus, by providing textual description and video tour on how to access it from the main gate of the campus.

The design phase involves designing the sitemap, creating the storyboard and building user interface design. It was important to design the sitemap so that the navigational flow of the tour app could be defined in a systematic approach. It was decided that the tour should employ a two-tier navigation only, therefore, in the sitemap design, the virtual campus tour were categorised into three main menus which were academic, administration and college.

Under each menu, only one-tier submenus were defined, for example, under Academic, all academic related building names were listed such as classroom buildings, selected laboratory and sports complex. For Administration menu, the corresponding destinations were buildings of academic affairs, student affairs, administration, grand hall, university clinic and library. For college menu, it was divided into two types called Siswa and Siswi, with each representing male and female residentials. Preparation of storyboard in design phase is useful to ease the development process because it helps in assigning the correct images and videos for each screen. Developer can illustrates the flow of direction on how to find the destination around university campus. The purpose of this storyboard is to visualize the venues where the video and image would be captured.

Balsamiq software was used to design user interfaces for the virtual tour, while Eclipse was used to develop the interface of the tour. Advantages of using Eclipse is it is free and open source, and this software can be used to develop applications in other languages such as C++, Ruby, HTML5, and PHP. Then, royalty-free background music for the video were added. 
When it comes to collecting assets for panoramic video, the Xiaomi Mi Sphere Camera Kit 360 Degree was used to make the video recording and to capture images surrounding selected university area. Administrative building, academic blocks and residential college were the prime area for the tour. The camera two lenses will automatically calibrate and adjust the image and colours to ensure the video recording is smooth. This camera is perfect for indoor, outdoor, travel, business, journalism, film and other uses. For this project, one of the researchers rode a motorcycle as a passenger, held the camera using one hand and the motorcyclist drove around campus at low speed.

The development phase is the process of authoring and producing materials. MAGIX Video Pro X was used to assemble the assets into one smooth web app. It was chosen because it offers professional video editing capability at a typical user level program. Figure 1 and Figure 2 show the interface of virtual campus tour app. Every page inside the system will show the video and information about the respective location. Each buildings are labeled and user can rotate the video in 360 degree.

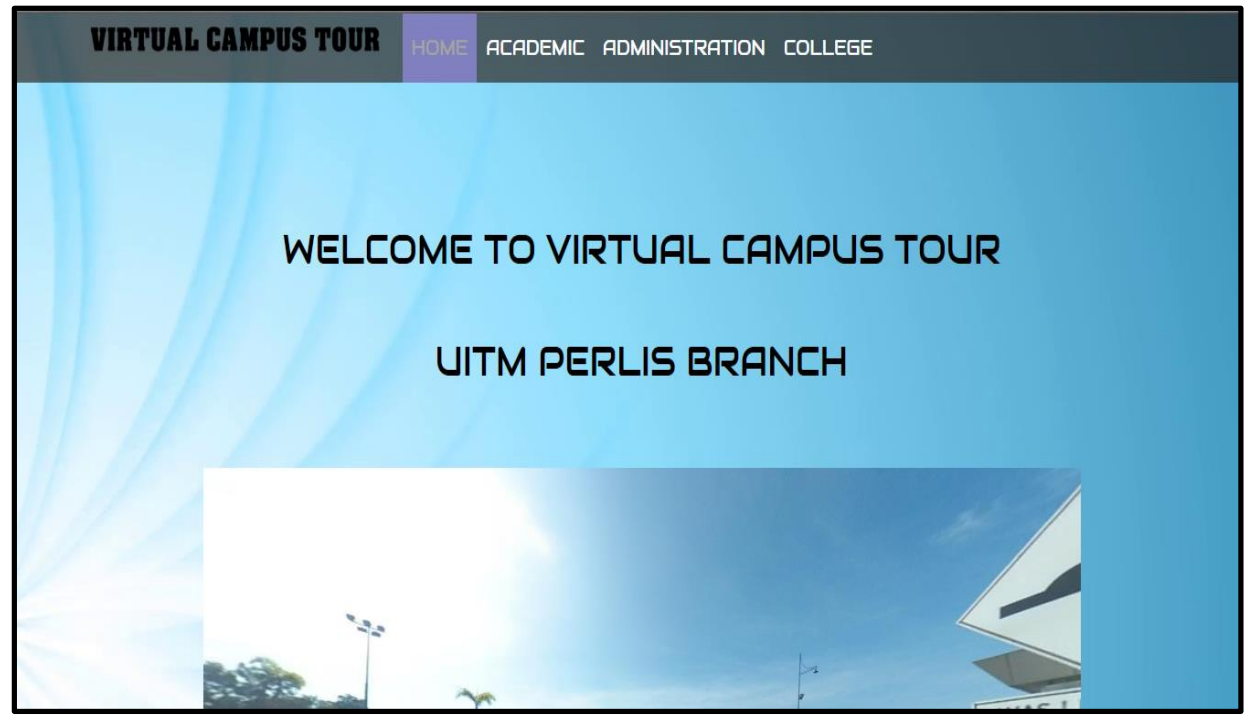

Figure 1: Screenshot of Homepage interface

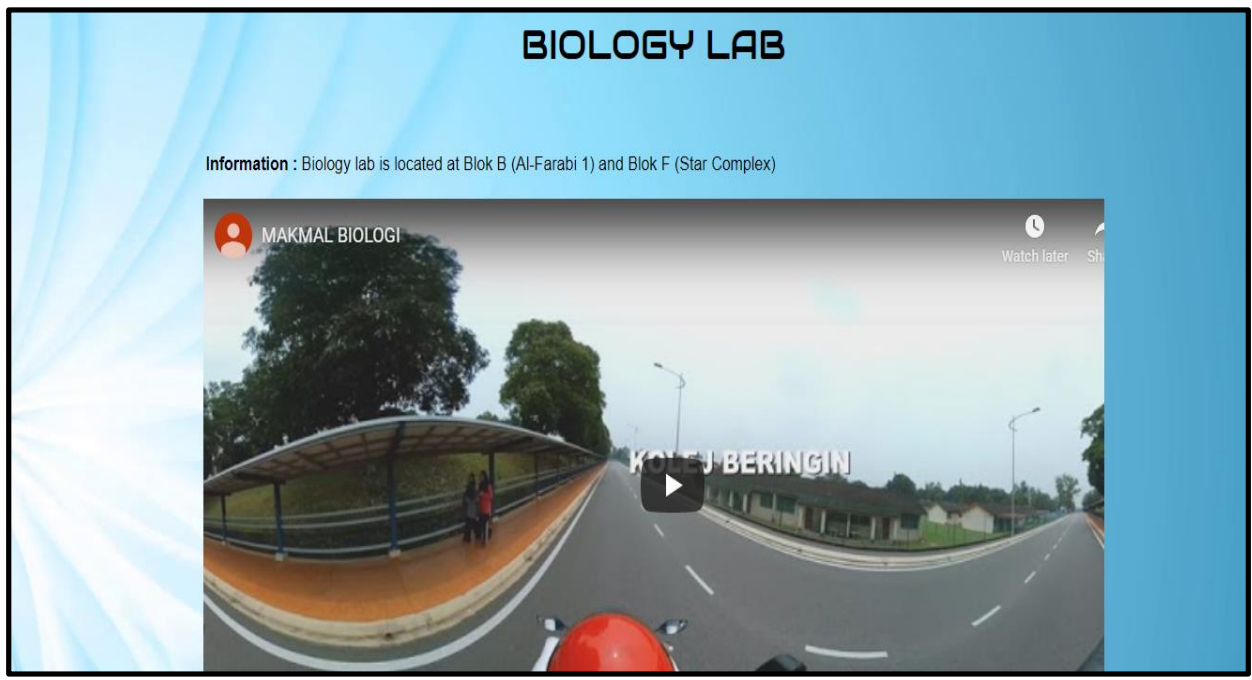

Figure 2: Screenshot of direction to the Biology Lab interface 


\section{HEURISTIC EVALUATION}

In test phase, a heuristic evaluation was done with experts to evaluate the features and functionality of the system, in which they can check the system whether it is perfectly functioning based on requirement and design specifications. This evaluation is important to ensure that the system works effectively and smoothly. Five experts participated in evaluating the system. The experts were university lecturers who have 10 to 25 years of professional experience in the computer science field. Heuristic evaluation contains several criteria that need to be evaluated by the experts. The criteria are visibility of system status, match between system and real world, user control and freedom, consistency and standard, flexibility and minimalist design, aesthetic and minimalist design, help and documentation, and error control. Each criteria can be rated using 5-point Likert Scale ranging from Strongly Disagree (1) to Strongly Agree (5).

\section{FINDINGS AND DISCUSSION}

This section discusses the results of the heuristic evaluation from analysis of descriptive statistic, that is mean score of every usability aspect, and followed by qualitative data analysis based on comments and recommendations given by the experts. For each criteria of usability, there were more than one questions. For example, in visibility of system status, experts were required to rate their opinion whether each screen has descriptive title, whether they knew where to go from current location and whether the information given matched what they wanted to find. This aspect received mean score of 4.2, which could imply that the virtual campus tour app showed its system status clearly to the users.

For the second usability measure, match between system and real world, the questions required experts to assess whether the menus were ordered in logical way, easily comprehensible categories of menu items, used appropriate theme colours and used clear-cut language. With mean score of 4.2, it shows that the app speaks users' language and follows convention that users are familiar with.

From the aspect of user control and freedom, it measures two of the most important features of the app which was its partitioning strategy and video. Therefore, experts were asked to rate how easy it was to access all segments of the app and how easy it was to play the video. Receiving mean score of 4.6, this could indicate that the app was accepted as having sufficient autonomy. This is especially important for an app that is intended to show location of selected destinations by showing its journey in the form of panoramic video. Users do need to be given power in controlling their choices of destinations and controlling the video (for example to move forward, to rewind and to stop).

Moving on to the fourth aspect which is consistency and standards, it assesses whether each page has title and if it uses high quality pictures and videos to grab attention. This attribute obtained mean score of 4.3, which means all experts relatively agreed that the app was consistent and kept to standards.

Furthermore, in terms of flexibility and minimalist design, it focuses on the menu list, which should be short. A mean score of 4.2 shows that the app has indeed used simple, yet understandable labels in the menu list. For minimalist design and aesthetic wise, the mean score of 4.0 could mean that experts agree 
the virtual campus tour app has simple and clear screen structure, as well as shows relevant information only in each screen.

In the area of help and documentation, it measures the app whether information is given at every page, and whether the visual layout is well-designed. Its mean score of 4.4 might be a good early indicator that experts agreed there was sufficient information in every screen, and that each screen has neat graphical arrangement.

Nevertheless, experts were neutral in aspects related to error control (mean score of 3.4), which concentrated on error prevention, and helping users recognize, diagnose and recover from errors. This could be due to the fact that the app does not display error messages since users do not need to key in any data or perform any computation, instead, they could only click on items in the menus in the main screen. This is a usability element that must be addressed for improving the app.

The last part of the heuristic evaluation allowed experts to give comments for improvement of the app. This was analysed from qualitative perspective. From the five comments, the issues raised were mainly about adding visual information in the form of campus-wide map, upgrading the help section and changing the fonts type and size to justify its design.

Among the improvements made were adding 2D map into the homepage interface so that users could refer to it to visualize the exact locations of buildings and areas covered in the campus. This is especially useful if they are lost and need to locate their path. Next, Help menu was also added to provide short and concise on-site assistance should the user feel confused when using an unfamiliar system for the first time. Help consists of tips on how to use the app effectively. Additionally, from design perspective, an expert commented about the use of serif font which is Times New Roman in the informative page containing description of a particular destination, which the expert considered as unsuitable. Therefore it was changed into sans serif font which is Arial. Beside that, another comment was about the awkward size of textual label in the video. Figure 3 shows the size of font in the video before it was changed to smaller size so that the text can be easily read by the user, as shown in Figure 4.

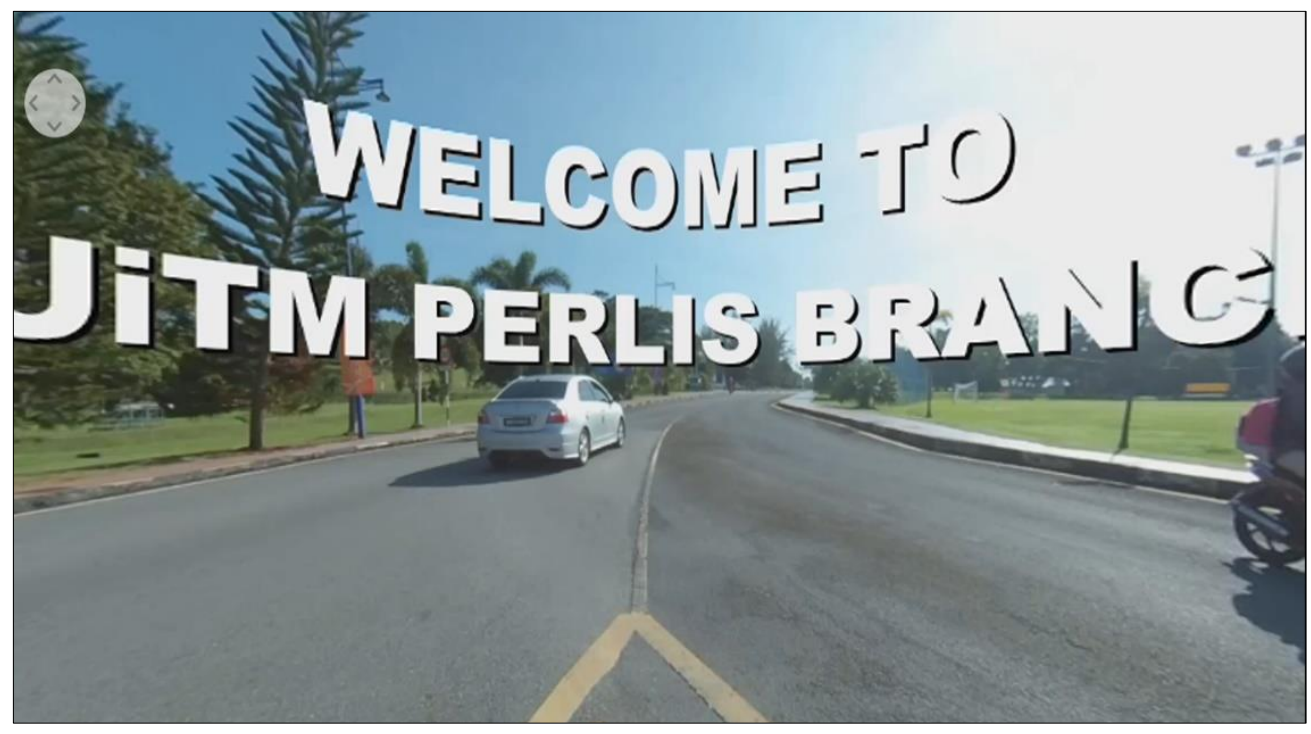


Figure 3: Labeling before font size change

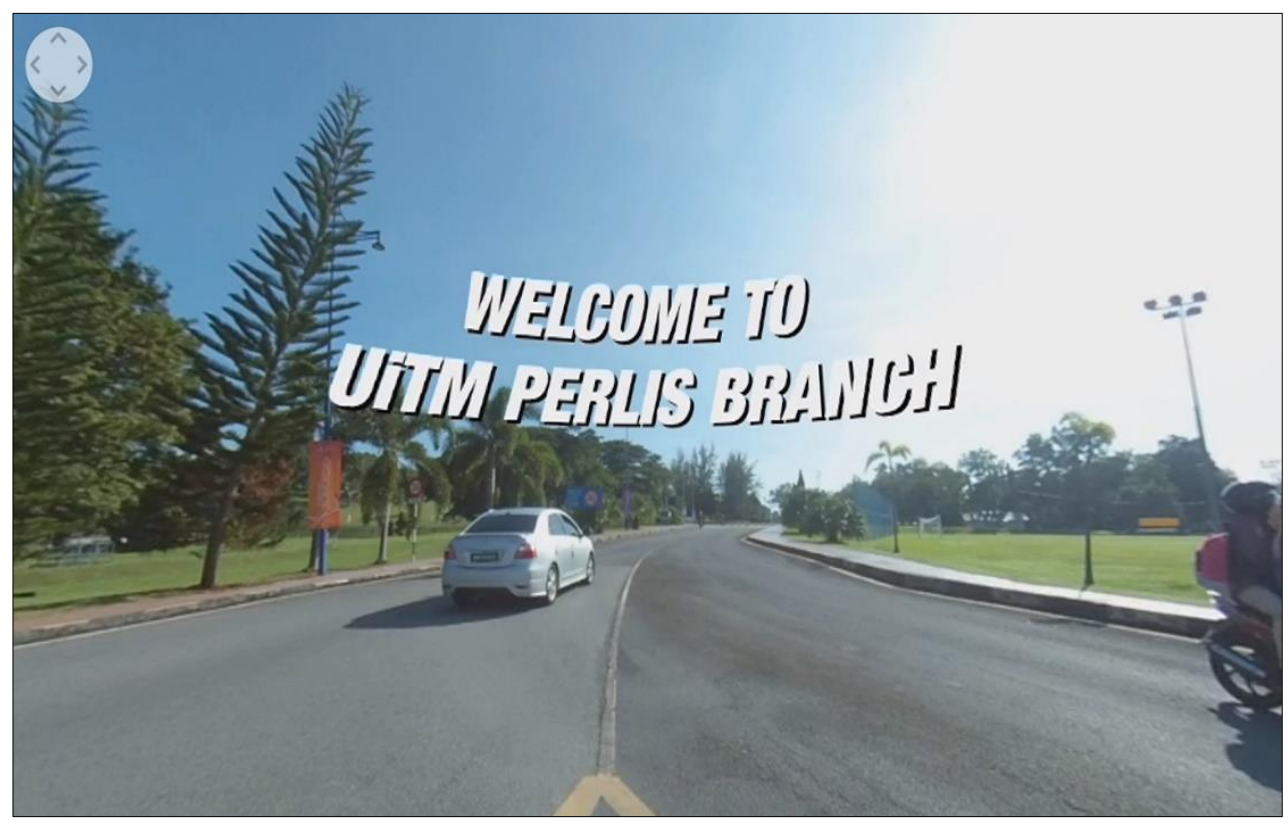

Figure 4: Labeling after font size change

\section{CONCLUSION}

The Virtual Campus Tour is a web app that helps university students, university staffs and visitors to discover desired destinations in the campus. The tour not only aid users via a $2 \mathrm{D}$ map, it also enhances the user experience in the exploring destinations in the campus via 360 degree panoramic video and images. A heuristic evaluation with five experts helped in finding usability problems and upgrading some design features of the tour before having another set of test, a user acceptance test with the user representatives in the next iteration. For future work, this app could be enhanced with augmented reality features where users could use their device such as a tablet or smartphone to aim at a selected marked building, then its essential information and relevant room photos will be displayed.

\section{REFERENCES}

Bakre, N., Deshmukh, A., Sapaliga, P., \& Doulatramani, Y. (2017). Campus Virtual Tour. International Journal of Advanced Research in Computer Engineering \& Technology (IJARCET), 6(4), 5.

Koyuncu, B., \& Kocabasoglu, P. N. (2008). Virtual campus. WSEAS International Conference. Proceedings. Mathematics and Computers in Science and Engineering. World Scientific and Engineering Academy and Society, Ankara, Turkey

Namsong, S. (2009). Virtual Campus Tour. In 14th Annual Technology, Colleges, and Community Worldwide Online Conference, Honolulu, USA. 
Perdana, D., Irawan, A. I., \& Munadi, R. (2019). Implementation of a web based campus virtual tour for introducing Telkom university building. International Journal if Simulation-Systems, Science \& Technology, 20(1), 1-6.

Rohizan, R. B., Vistro, D. M., \& Puasa, M. R. B. (2019, May). Enhanced Visitor Experience Through Campus Virtual Tour. In Journal of Physics: Conference Series (Vol. 1228, No. 1, p. 012067). IOP Publishing.

Sharma, S., Sarkar, D., \& Gupta, D. (2012). Agile Processes and Methodologies: A Conceptual Study. International Journal on Computer Science and Engineering, 4.

Widiyaningtyas, T., Prasetya, D. D., and Wibawa, A. P. "Adaptive Campus Virtual Tour using LocationBased Services," 2018 Electrical Power, Electronics, Communications, Controls and Informatics Seminar (EECCIS), Batu, East Java, Indonesia, 2018, pp. 419-423, doi: 10.1109/EECCIS.2018.8692853.

Wook, T.S., Zairon, I.Y., Idris, M., Zin, N.A., Judi, H.M., \& Jailani, N. (2018). Campus Virtual Tour Design to Enhance Visitor Experience and Interaction in a Natural Environment. The International Journal of Multimedia \& Its Applications, 10, 77-92. https://doi.org/10.5121/ijma.2018.10307. 